\title{
Identification of Phosphorylation Sites in Phosphopeptides by Positive and Negative Mode Electrospray Ionization-Tandem Mass Spectrometry
}

\author{
Mark Busman, Kevin L. Schey, John E. Oatis, Jr., and Daniel R. Knapp \\ Department of Pharmacology, Medical University of South Carolina, Charleston, South Carolina, USA
}

\begin{abstract}
A series of synthetic mono- and diphosphorylated peptides has been analyzed by positive and negative mode electrospray ionization-tandem mass spectrometry. The synthetic peptides are serine- and threonine-phosphorylated analogs of proteolytic fragments from the C-terminal region of rhodopsin. Use of positive and negative modes of electrospray ionization to produce ions for tandem mass spectrometry via low energy collision-induced dissociation was explored. For some of the peptides, the complementary use of experimental results allowed determination of the phosphorylation sites when either mode alone gave incomplete information. Other peptides, however, gave negative ion spectra not interpretable in terms of backbone cleavages. However, use of positive ion tandem mass spectrometry of different charge state precursor ions gave sufficient information in most cases to assign sites of phosphorylation. These results illustrate the utility of obtaining complementary information by tandem mass spectrometry by using precursor ions of different charge polarity or number. (J Am Soc Mass Spectrom 1996, 7, 243-249)
\end{abstract}

$\mathrm{M}$ ass spectrometry has been demonstrated to be useful for the analysis of the phosphopeptides that result from digests of phosphorylated proteins [1-3]. Mass spectrometric methods can be used to identify phosphopeptides in peptide mixtures, as well as to elucidate the structures of the identified phosphopeptides, which include determination of the site(s) of phosphorylation in peptides that contain multiple potential phosphorylation sites [4].

For peptides of known sequence, the degree of phosphorylation can be determined quickly by increases of $80 \mathrm{u}$ in the measured molecular weight, as compared to the molecular weight calculated from the peptide sequence $[2,5]$. Fast-atom bombardment (FAB) ionization has been used extensively for this purpose. [In this discussion the label "fast-atom bombardment (FAB)" ionization is used in the generic sense, which includes other related ionization techniques that utilize the impact of accelerated ions to achieve analyte ionization. Use of these related techniques often is referred to as liquid secondary ionization mass spectrometry.] However, it is clear that, due to their lower surface activity in FAB matrices, phosphopeptide ions often are ionized with lower efficiency than their nonphosphorylated analogs [6]. Alternatively, two newer ionization techniques-matrix-assisted laser desorp-

Address reprint requests to Dr. Daniel R. Knapp, Department of Pharmacology, Medical University of South Carolina, Charleston, SC 29425-2251. tion ionization [7] and electrospray ionization (ESI) [8] - have been shown to be recently effective methods to achieve the efficient ionization of phosphorylated peptides. Moreover, for mass analysis, both techniques are capable of ionization of much larger molecules than previously possible with FAB [9]. This capability allows mass analysis of the phosphorylated protein prior to enzymatic digestion [10]. In cases where molecular weight and/or sequence information is available for the nonphosphorylated protein, the degree of phosphorylation of the intact protein easily is determined.

For structure elucidation of phosphopeptides, fragmentation upon FAB ionization has been of some utility $[5,11-13]$. Similarly, a number of applications of fast-atom bombardment tandem mass spectrometry (FAB-MS/MS) for determination of sites of phosphorylation have been reported [1, 9, 14-17]. Collisional activation also has been utilized with ESI-generated phosphopeptide ions. A variety of approaches that utilize collisional activation of ESI-generated phosphopeptide ions have been demonstrated as diagnostic tests for the presence of a phosphorylation site in a peptide $[18,19]$. For peptides that contain multiple sites and/or potential sites of phosphorylation, electrospray ionization tandem mass spectrometry (ESIMS/MS) has been shown to be useful in location of phosphorylation sites. In 1991, Michel et al. [15] and Alexander et al. [16] reported the use of ESI-MS/MS with a triple quadrupole mass spectrometer in conjunction with FAB-MS/MS studies of phosphorylation 
in spinach light-harvesting chlorophyll protein II and bovine brain class III $\beta$ tubulin, respectively. Since then, ESI-MS/MS has been utilized for studies of phosphorylation in recombinant mitogen-activated protein kinase $\mathrm{p} 42^{\text {mapk }}$ [20], heparin-binding fibroplast growth factor receptor tyrosine kinase $(f l g)[21], \alpha_{\mathrm{s} 1}$ casein [22], and bovine brain GAP-43 [23]. Recently, the cysteine phosphorylation in the glucose transporter of E. coli was studied by ESI-MS/MS [24].

Rhodopsin and rhodopsin kinase phosphorylations have been studied by ESI-MS/MS [25-27] and FABMS/MS [28]. In our studies of rhodopsin phosphorylation we have synthesized a series of reference phosphopeptides, which correspond to the peptides from the C-terminal region that could be isolated after enzymatic digestion of rhodopsin [29,28]. A complete set of mono- and diphosphorylated analogs of the fragment peptides ASTTVSKTE and TSQVAPA was synthesized. Tandem mass spectrometric analyses of the peptides via FAB ionization were hampered by a low ionization efficiency for the phosphorylated species [28]. Here we report the results of the analysis of these synthetic peptides by ESI-MS/MS and, in particular, the complementary use experiments that utilize positive and negative ions as precursor ions for collisioninduced dissociation (CID).

\section{Experimental}

\section{Synthesis}

The preparation of the synthetic phosphorylated peptides has been described previously [29]. The peptides were analyzed, without purification, directly from the crude reaction product. The desired phosphopeptides were minor components of the product mixtures (presumably due to decomposition upon storage of the crude products), that constituted $\sim 1-10 \%$ of the product mixtures [as observed by electrospray ionization mass spectrometry (ESI-MS)].

\section{Electrospray Ionization Mass Spectrometry}

Peptides were analyzed by ESI-MS on a Sciex (Thornhill, Ontario) API III triple quadrupole mass spectrometer. Solutions of the peptides were prepared at a concentration of $\sim 1 \times 10^{-4} \mathrm{M}$ (the crude reaction product was assumed to contain only the desired peptide) in $47.5 / 47.5 / 5(\mathrm{v} / \mathrm{v} / \mathrm{v})$ methanol-water-acetic acid for positive mode $(+)$ ESI-MS and methanolwater-piperidine for negative mode (-)ESI-MS. Solutions were infused at $\sim 10 \mu \mathrm{L} / \mathrm{min}$ to the pneumatically assisted ESI interface with a Harvard Apparatus (South Nattick, MA) Model 11 syringe pump. High purity air and ultrahigh purity nitrogen were used as the nebulization and curtain gases, respectively. The nebulization gas was unheated and the curtain gas was heated to $\sim 55^{\circ} \mathrm{C}$. Interface voltages were adjusted to provide high molecular ion current for the peptides analyzed. An effort was made to minimize losses of molecular ion signal, caused by solvent adduction, while minimizing dissociations in the interface region. Assignments of peaks (according to the peak top mass-to-charge ratio value) were based upon calculations of average masses for the peptides.

\section{Tandem Mass Spectrometry}

CID was carried out in the rf-only quadrupole region Q2 to generate product ions from peptide precursor ions. A 90/10 mixture of argon and nitrogen was used as the target gas. Commonly, the collision cell pressure was adjusted to provide $\sim 50 \%$ attenuation of the parent ion signal. The voltage on $\mathrm{Q} 2$ was adjusted to control collision energies (ordinarily in the range of $55-85$ V Q1-Q2 bias). Collision cell pressure and collision energy were adjusted to provide a useful degree of fragmentation. For product ion scans, Q1 was set to pass a 2-3 m/z window, whereas Q3 was set at unit resolution.

The product ions from the CID experiments were labeled in accordance with the Biemann nomenclature [3]. For convenience, the fragments from the CID experiments for negatively charged ions also were labeled in accordance with the Biemann nomenclature [30]. Use of the nomenclature for negatively charged fragments does not imply any assumptions with regard to their structures. Instead we have chosen to label " $\mathrm{b}$ " and " $\mathrm{y}$ " ions as ions that have a mass-tocharge ratio two units less than their positively charged counterparts (in the case of singly charged fragment ions). It should be noted that Bradford et al. [31] have suggested recently an alternative nomenclature for the fragment ions from CID of negatively charged peptides.

\section{Results}

\section{Tandem Mass Spectrometry of TSQVAPA}

The product ion spectrum for the $[\mathrm{M}+\mathrm{H}]^{+1}$ ion of TSQVAPA is shown in Figure 1a. The peaks in the spectrum correspond to $y$ - and b-type fragment ions. The product ion spectrum for the $[\mathrm{M}-\mathrm{H}]^{-1}$ ion of TSQVAPA is shown in Figure 1b. Similar fragmentation information is accessible from the peaks in this spectrum. Sufficient fragmentation information is provided by either spectrum to unambiguously confirm the peptide's sequence. Fragmentation information from TSQVAPA is summarized in Table 1.

\section{Tandem Mass Spectrometry of Monophosphorylated TSQVAPA}

The product ion spectrum for the $[\mathrm{M}+\mathrm{H}]^{+1}$ ion of T(p)SQVAPA is shown in Figure 2a. The commonly observed loss of $98 \mathrm{~m} / z$ units from the $[\mathrm{M}+\mathrm{H}]^{+1}$ ion, which corresponds to a loss of $\mathrm{H}_{3} \mathrm{PO}_{4}$, is seen [17]. Similar to the spectrum for the nonphosphorylated 


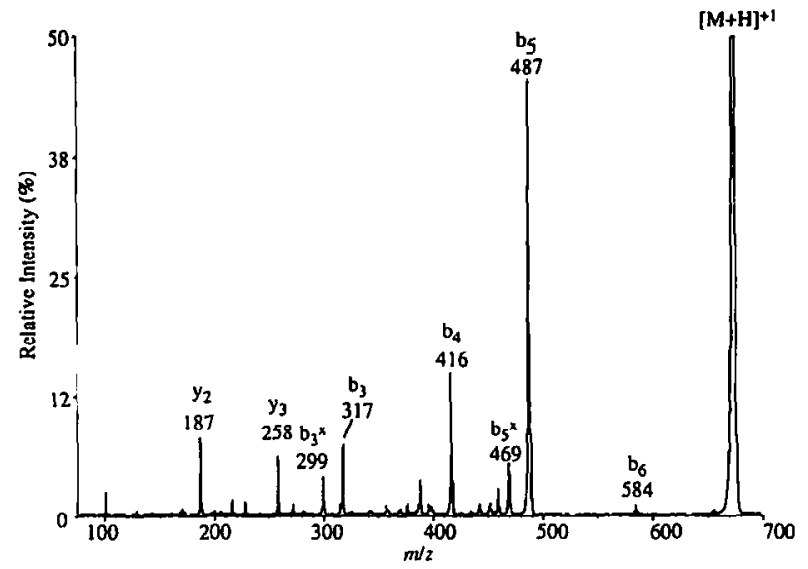

b

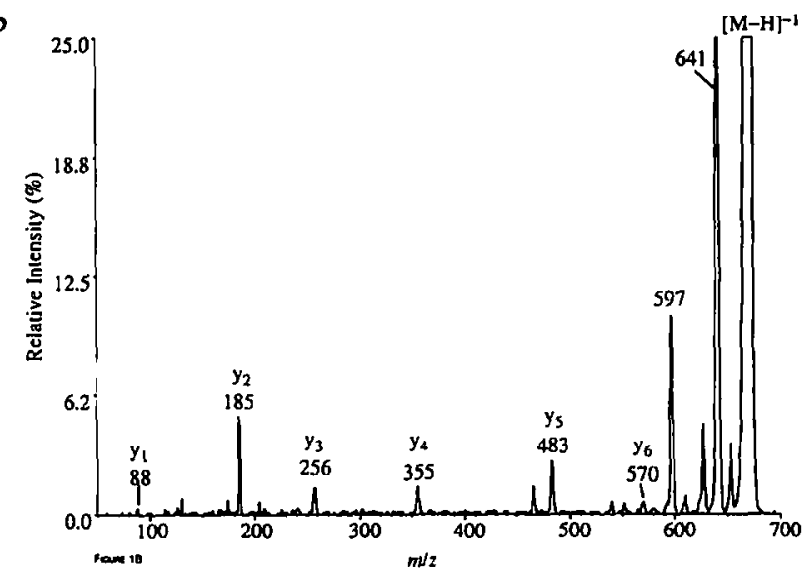

Figure 1. Product ion spectra for the (a) $[\mathrm{M}+\mathrm{H}]^{+1}(m / z$ 674) and (b) $[\mathrm{M}-\mathrm{H}]^{-1}(\mathrm{~m} / \mathrm{z}$ 672) ions of the peptide TSQVAPA. Ions that correspond to a loss of 18 from b-type fragment ions are labeled with an $x$.

analog, both y-and b-type fragments are observed. As with the $[\mathrm{M}+\mathrm{H}]^{+1}$ ion, losses of $98 \mathrm{~m} / z$ units are seen from the b-type ions that contain the phosphate group. The results of the CID experiments on the $[\mathrm{M}+\mathrm{H}]^{+1}$ ions of the two monophosphorylated TSQVAPA peptides T(p)SQVAPA and TS(p)QVAPA are summarized in Table 1 . It is clear that sufficient fragmentation information is not provided from the product ion spectra of the $[\mathrm{M}+\mathrm{H}]^{+1}$ ions alone to unequivocally assign location of the sites of phosphorylation on each peptide. The product ion spectrum for the $[\mathrm{M}-\mathrm{H}]^{-1}$ ion of T(p)SQVAPA is shown in Figure $2 \mathrm{~b}$. Although the product ion spectra from the $[\mathrm{M}-$ $\mathrm{H}]^{-1}$ ions alone do not provide sufficient information to deduce the complete sequence of the peptides, it is apparent that the CID experiments on $[\mathrm{M}+\mathrm{H}]^{+1}$ and $[\mathrm{M}-\mathrm{H}]^{-1}$ ions provide complementary information that allows assignment of the sequence, which includes site of phosphorylation.

\section{Tandem Mass Spectrometry of Diphosphorylated TSQVAPA}

The product ion information is summarized in Table 1. Because the peptide contains only two hydroxy-amino acids, the determination of phosphorylation sites constitutes a trivial case. However, the combination of product ion information from both the $[\mathrm{M}+\mathrm{H}]^{+1}$ and $[\mathrm{M}-\mathrm{H}]{ }^{1}$ ions provides nearly complete sequence information, which includes sites of phosphorylation. Interestingly, in the product ion spectra for the $[\mathrm{M}-\mathrm{H}]^{-1}$ ion, product ions that correspond to $[\mathrm{M}-$ $\mathrm{H}-98]^{-1}$ and $[\mathrm{M}-\mathrm{H}-196]^{-1}$ are major peaks (data not shown). These peaks, which represent neutral losses of $\mathrm{H}_{3} \mathrm{PO}_{4}$, could arise from two possible mechanisms. First, even with diphosphorylated peptides, ions could enter the activation process with the negative charge that resides in positions other than on one of the phosphate groups. A second alternative would be that during the dissociation process the negative charge that resides on a cleaving phosphate group could be transferred from the phosphate group to another site in the peptide.

\section{Tandem Mass Spectrometry of ASTTVSKTE}

The product ion spectrum for the $[\mathrm{M}+\mathrm{H}]^{+1}$ ion for ASTTVSKTE is shown in Figure 3a. A similar spectrum

Table 1. Fragments of TSQVAPA and phosphorylated derivatives ${ }^{a}$

\begin{tabular}{|c|c|c|c|c|c|c|}
\hline Peptide & $b_{1}, y_{6}$ & $b_{2}, v_{5}$ & $b_{3}, y_{4}$ & $b_{4}, y_{3}$ & $b_{5}, y_{2}$ & $b_{6}, v_{1}$ \\
\hline $\begin{array}{r}\text { TSOVAPAl+) } \\
\text { (Figure 1a) }\end{array}$ & & & b & $b, y$ & $b, y$ & $b$ \\
\hline $\begin{array}{c}\text { TSQVAPAI - } \\
\text { (Figure 1b) }\end{array}$ & $y$ & $y$ & $y$ & $\gamma$ & $y$ & $y$ \\
\hline $\begin{array}{l}\text { T(p)SOVAPA(+) } \\
\text { (Figure 2a) }\end{array}$ & & $b^{*}$ & $b, b^{*}$ & b. $b^{\star}, y$ & b, $b^{\star}, y$ & \\
\hline $\begin{array}{l}\text { T(p)SQVAPA(-) } \\
\text { (Figure 2b) }\end{array}$ & b & b. y & $y$ & $y$ & $y$ & \\
\hline TS(p)OVAPA(+) & & $y$ & $b, b^{\star}, y$ & $b, b^{\star}, y$ & $b, b^{*}, y$ & \\
\hline TS(p)OVAPAl - ) & $y^{*}$ & $y$ & $y$ & $y$ & $y$ & \\
\hline T(p)S(p)QVAPA(+) & & & & $b, y$ & b, $y$ & \\
\hline T(p)S(p)OVAPAI-) & $y^{\star}$ & $y$ & $y$ & $y$ & $y$ & \\
\hline
\end{tabular}

${ }^{3}$ Ions labeled with an asterisk (*) indicate ions detected with the loss of 98 u (one $\mathrm{H}_{3} \mathrm{PO}_{4}$ molecule). 


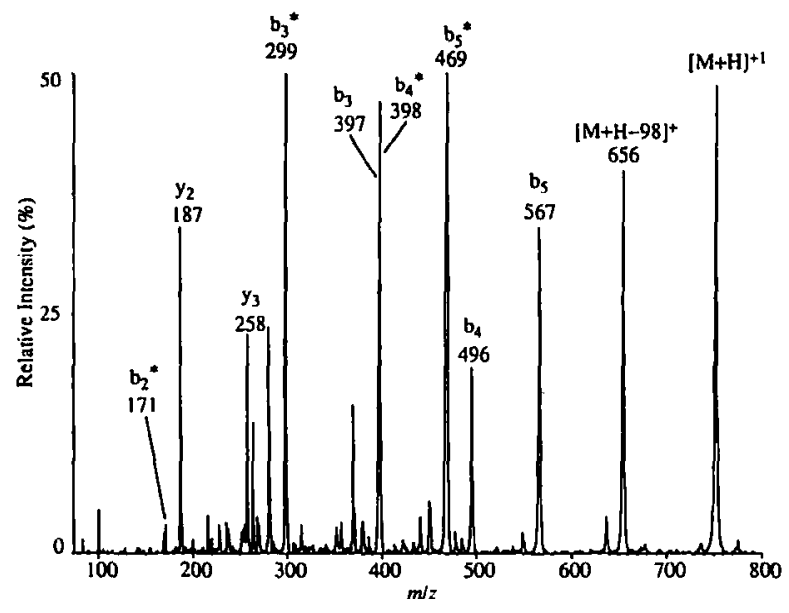

b

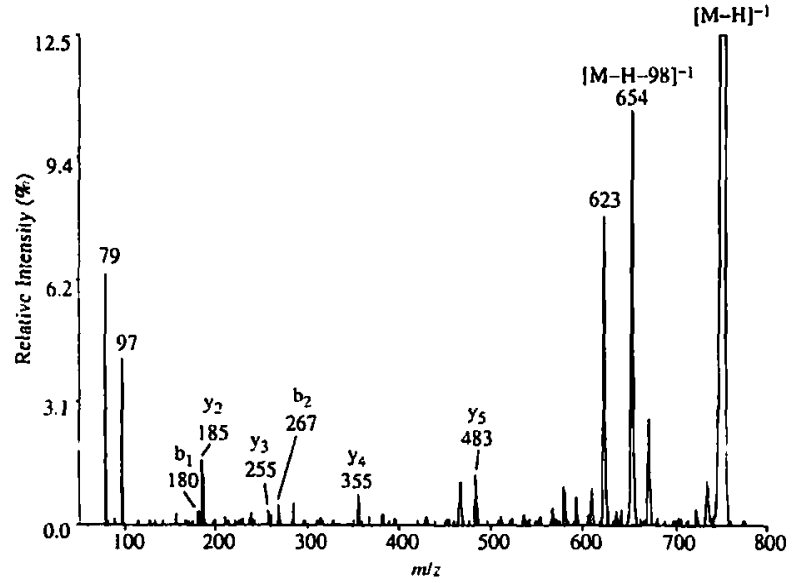

Figure 2. Product ion spectra for the (a) $[\mathrm{M}+\mathrm{H}]^{+1}(m / z$ 754) and (b) $[M-H]^{-1}(m / z$ 752) ions of the peptide T(p)SQVAPA. Fragment ions observed with a loss of 98 are labeled with an asterisk $\left(^{*}\right)$.

for the $[\mathrm{M}+2 \mathrm{H}]^{+2}$ ion is shown in Figure 3b. Many peaks in each spectrum can be assigned as $y$ - and b-type product ions. Fragmentation information from the two spectra is summarized in Table 2. Although neither spectrum alone allows complete assignment of the peptide sequence, the combination of the information from both spectra does unambiguously provide complete sequence information.

\section{Tandem Mass Spectrometry of Monophosphorylated ASTTVSKTE}

The product ion spectra for the $[\mathrm{M}+\mathrm{H}]^{+1}$ and $[\mathrm{M}+$ $2 \mathrm{H}]^{+2}$ ions of AS(p)TTVSKTE are shown in Figure 4. Losses of $\mathrm{H}_{3} \mathrm{PO}_{4}$, indicated by a loss of $98 \mathrm{~m} / z$ units (or in the case of the doubly charged species, $-49 \mathrm{~m} / \mathrm{z}$ units) from the $[\mathrm{M}+\mathrm{H}]^{+1},[\mathrm{M}+2 \mathrm{H}]^{+2}$, and, where appropriate, the $\mathrm{y}$ - and b-type product ions are seen. Results from the product ion spectra for the $[\mathrm{M}+\mathrm{H}]^{+1}$ and $[\mathrm{M}+2 \mathrm{H}]^{+2}$ ions of the monophosphorylated ASTTVSKTE analogs are summarized in Table 2 . The
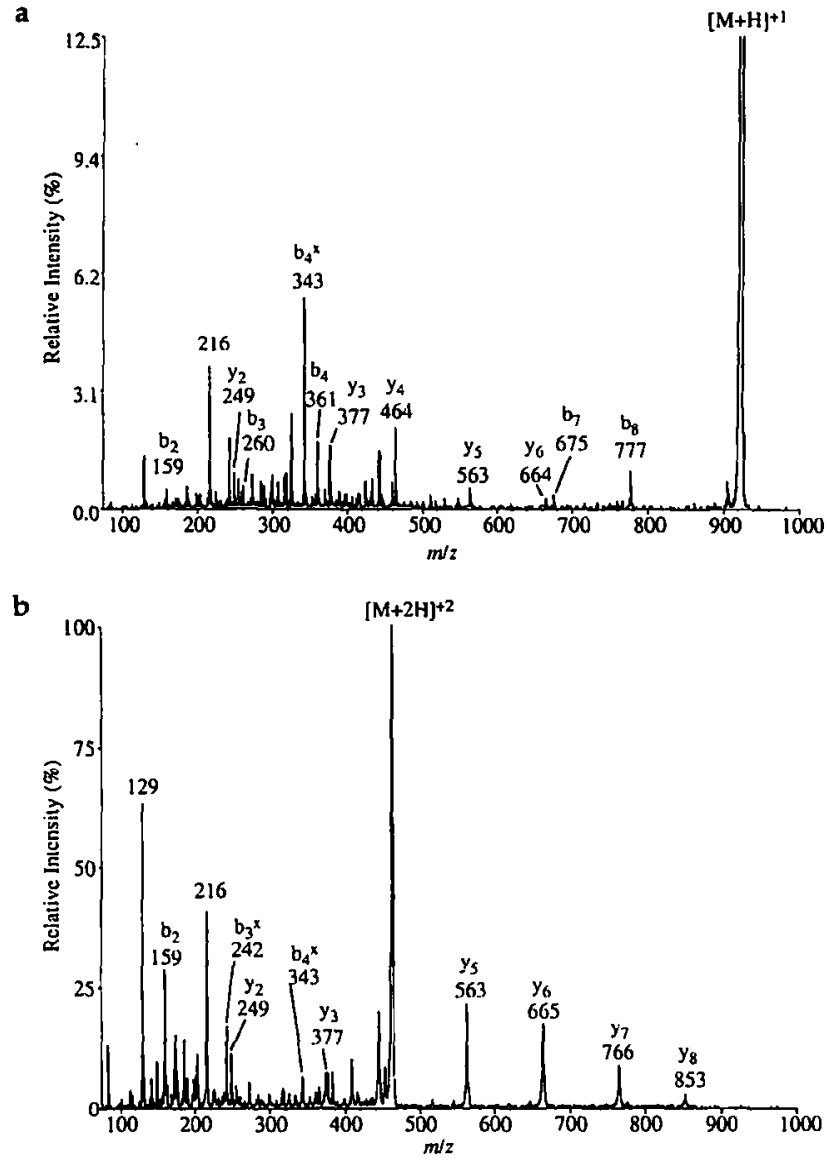

Figure 3. Product ion spectra for the (a) $[\mathrm{M}+\mathrm{H}]^{+1}(m / z$ 924) and (b) $[\mathrm{M}+2 \mathrm{H}]^{+2}(m / z 463)$ ions of the peptide ASTTVSKTE. Ions that correspond to a loss of 18 from b-type fragment ions are labeled with an $x$.

results of the CID experiments on the two charge states provide complementary information that allows unequivocal assignment of the location of all sites of phosphorylation.

\section{Tandem Mass Spectrometry of Diphosphorylated ASTTVSKTE}

Figure 5 shows product ion spectra for the $[\mathrm{M}+\mathrm{H}]^{+1}$ and $[\mathrm{M}+2 \mathrm{H}]^{+2}$ ions of AST(p)TVS(p)KTE, as an example of 1 of the 10 isomeric diphosphopeptides. Again, the spectra can be interpreted in terms of yand b-type fragmentations, as well as removal of one $(-98 \mathrm{u})$ or two $(-196 \mathrm{u})$ molecules of $\mathrm{H}_{3} \mathrm{PO}_{4}$. The results of the experiments on the diphosphorylated ASTTVSKTE peptides are summarized in Table 2. However, unequivocal assignments of phosphorylation sites on all diphosphorylated peptides were not accessible, even from the complementary use of the results from the experiments from the +1 and +2 charge states. 
Table 2. Fragments of ASTTVSKTE and phosphorylated derivatives ${ }^{a}$

\begin{tabular}{|c|c|c|c|c|c|c|c|c|}
\hline Peptide & $b_{1}, y_{8}$ & $b_{2}, y_{7}$ & $b_{3}, y_{6}$ & $b_{4}, y_{5}$ & $b_{5}, y_{4}$ & $b_{6}, y_{3}$ & $b_{7}, y_{2}$ & $b_{8}, y_{1}$ \\
\hline $\begin{array}{l}\text { ASTTVSKTE(+1) } \\
\text { (Figure 3a) }\end{array}$ & & $b$ & b, y & $b, y$ & $y$ & $y$ & b. $y$ & $b$ \\
\hline $\begin{array}{l}\text { ASTTVSKTE }(+2) \\
\text { (Figure } 3 b \text { ) }\end{array}$ & $y$ & b. y & $y$ & $y$ & & $y$ & $y$ & \\
\hline $\begin{array}{l}\text { AS(p)TTVSKTE(+1) } \\
\text { (Figure 4a) }\end{array}$ & & $y$ & $y$ & $b^{\star}, y$ & $\mathbf{b}^{\star}, y$ & $b^{\star}, y$ & $b^{\star}$ & $b^{\star}$ \\
\hline $\begin{array}{l}\text { AS(p)TTVSKTE(+2) } \\
\text { (Figure 4b) }\end{array}$ & $y, y^{*}$ & $b, b^{\star}, v$ & y & $y$ & $y$ & $y$ & $y$ & $y$ \\
\hline AST(p)TVSKTE(+1) & & $y^{\star}$ & $y$ & $b^{*}, y$ & $b^{\star}, y$ & $y$ & b. $y$ & b \\
\hline AST(p)TVSKTE(+2) & $b, y, y^{\star}$ & $b, y, y^{*}$ & $b, b^{\star}, y$ & $b^{\star}, y$ & $y$ & $b, y$ & $y$ & $y$ \\
\hline ASTT(p)VSKTE(+1) & & & $y^{*}$ & $b^{*}, y$ & $b^{\star}, y$ & $y$ & b & $b^{*}$ \\
\hline ASTT(p)VSKTE(+2) & $y$ & b. y & $b, y, y^{\star}$ & $b^{*}, y$ & b. $y$ & $b, y$ & b. $y$ & b. $y$ \\
\hline ASTTVS(p)KTE(+1) & & $y^{*}$ & $y^{*}$ & $y^{\star}$ & $\gamma^{\star}$ & $y$ & $\mathbf{b}^{\star}$ & $b^{\star}$ \\
\hline ASTTVS(p)KTE(+2) & $y$ & b. $y$ & b, y & b. $y$ & $y$ & $b, y$ & b. $y$ & b. $y$ \\
\hline ASTTVSKT(p)E(+1) & & $y$ & $y$ & b. $y$ & $y$ & $y$ & $\mathbf{b}^{\star}$ & $b^{\star}$ \\
\hline ASTTVSKT(p)E(+2) & $y$ & b, y & b, y & b. $y$ & $y$ & $y$ & b. $y$ & $y$ \\
\hline AS(p)T(p)TVSKTE(+1) & & $y^{\star}$ & $y$ & b. $y$ & $y$ & $y$ & $b^{*}$ & \\
\hline AS(p)T(p)TVSKTE(+2) & & $b, y, y^{\star}$ & $y$ & $b^{\star}, y$ & $y$ & $y$ & $y$ & $y$ \\
\hline AS(p)TT(p)VSKTE(+1) & & & $y^{\star}$ & $y$ & $y$ & y & $\mathbf{b}^{\star}$ & \\
\hline AS(p)TT(p)VSKTE(+2) & & & $y^{*}$ & $y$ & $y$ & $y$ & $y$ & \\
\hline AS(p)TTVS(p)KTE(+1) & & & & $y^{\star}$ & $y^{\star}$ & $y$ & $b^{\star \star}$ & $b^{*}$ \\
\hline AS(p)TTVS(p)KTE(+2) & & b, $y, y^{*}$ & $b^{\star}, y^{\star}$ & $b^{\star}$ & & $y$ & $y$ & $y$ \\
\hline AS(p)TTVSKT(p)E(+1) & & $y$ & & $b^{*}$ & $b^{*}, y$ & $b^{*}$ & $\mathbf{b}^{*}$ & $b^{* *}$ \\
\hline AS(p)TTVSKT(p)E(+2) & $y$ & b. $y$ & $b^{*}, y$ & $b^{*}, y$ & $b^{\star}$ & $y^{*}$ & $\gamma^{\star}$ & $y$ \\
\hline AST(p)T(p)VSKTE(+1) & & & & b & $y$ & & b & \\
\hline AST(p)T(p)VSKTE(+2) & & b. $y^{\star}, y^{\star \star}$ & $y^{*}$ & $y$ & $y$ & $y$ & $y$ & b, $y$ \\
\hline $\begin{array}{l}\text { AST(p)TVS(p)KTE(+1) } \\
\text { (Figure 5a) }\end{array}$ & & $y^{*}, y^{* \star}$ & $y^{\star}$ & $y^{\star}$ & $y^{\star}$ & $y$ & & \\
\hline $\begin{array}{l}\text { AST(p)TVS(p)KTE(+2) } \\
\text { (Figure 5b) }\end{array}$ & & b. $y^{\star}, y^{* *}$ & $y^{*}$ & $\mathbf{b}^{\star}$ & & & y & $b, y$ \\
\hline AST(p)TVSKT(p)E(+1) & & $y^{*}$ & $y$ & $y$ & $r$ & $y$ & & \\
\hline AST(p)TVSKT(p)E(+2) & & b. y & $y$ & $b^{*}, y$ & $y^{\star}$ & $y$ & $y^{\star}$ & \\
\hline ASTT(p)VS(p)KTE $(+1)$ & & & & $y^{*}$ & $y^{*}$ & & b & \\
\hline ASTT(p)VS(p)KTE(+2) & & b. y & $y, y^{\star}, y^{\star *}$ & $\mathbf{b}^{\star}$ & & & & y \\
\hline ASTT(p)VSKT(p)E(+1) & & & & $y$ & $\gamma$ & y & b & $\mathbf{b}$ \\
\hline ASTT(p)VSKT(p)E(+2) & & b. $y$ & b. $y$ & $b, y$ & $b^{\star}$ & b & b & $y$ \\
\hline ASTTVS(p)KT(p)E(+1) & & & & & $y$ & $b^{\star}, y$ & $b^{\star}$ & \\
\hline ASTTVS(p)KT(p)E(+2) & & $b, y$ & b. $y$ & b. y & $y$ & & $b^{\star}$ & $b^{*}$ \\
\hline
\end{tabular}

- Ions labeled with an asterisk $\left(^{\star}\right)$ indicate ions detected with the loss of $98 \mathrm{u}$ (one $\mathrm{H}_{3} \mathrm{PO}_{4}$ molecule); two asterisks (**) indicate ions detected with the loss $196 \mathrm{u}$ (two $\mathrm{H}_{3} \mathrm{PO}_{4}$ molecules).

Negative Electrospray Ionization Tandem Mass Spectrometry of ASTTVSKTE and Phosphorylated Analogs

Spurred by success of CID experiments on the [M $\mathrm{H}^{-1}$ ion of TSQVAPA, along with its phosphorylated analogues, we carried out product ion scans on the $[\mathrm{M}-\mathrm{H}]^{-1}$ and $[\mathrm{M}-2 \mathrm{H}]^{-2}$ ions of the ASTTVSKTE series of peptides. The spectra were not interpretable readily in terms of expected backbone fragmentations. Instead, a preliminary interpretation of CID spectra for the ASTTVSKTE peptide suggests that some product ions result from backbone cleavages, combined with side chain cleavages. These ions would be $b-$ and $y$-type product ions with masses reduced by side chain cleavages of the type suggested in Waugh and Bowie [32]. The interpretation of the spectra for the monoand diphosphorylated ASTTVSKTE peptides has been limited to preliminary assignments of side chain cleavages. Further work to utilize information from the CID experiments on $[\mathrm{M}-n \mathrm{H}]^{-n}$ ions is in progress. It is apparent that, in general, interpretation of peptide CID experiments on $[\mathrm{M}-n \mathrm{H}]^{-n}$ ions is not as straightforward as for $[\mathrm{M}+n \mathrm{H}]^{+n}$ ions. 


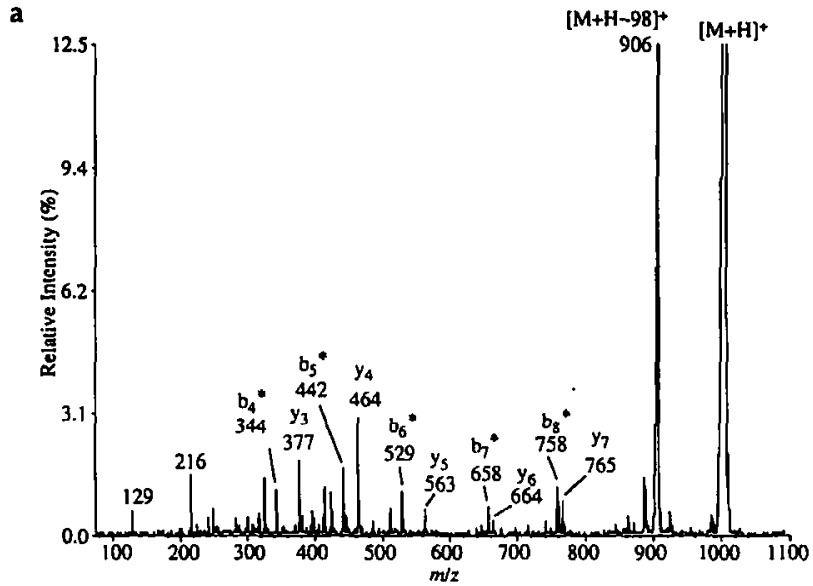

b

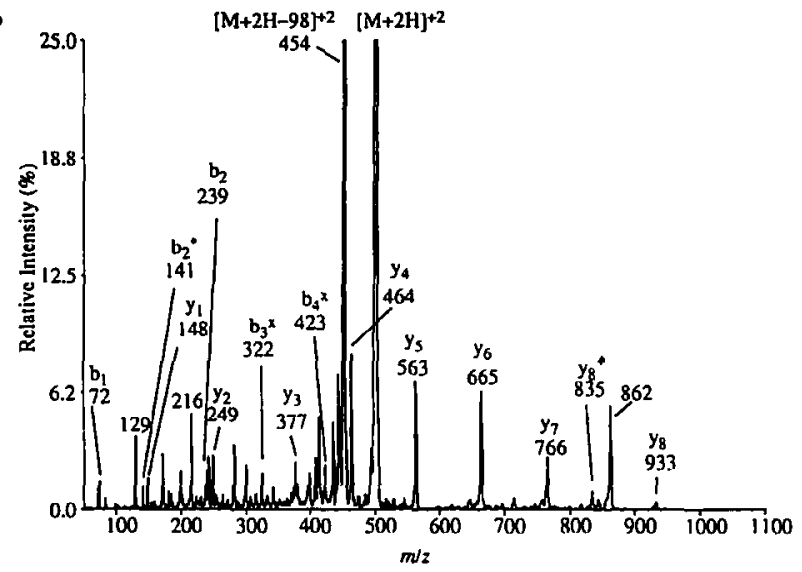

Figure 4. Product ion spectra for the (a) $[\mathrm{M}+\mathrm{H}]^{+1}(m / z$ 1004) and (b) $[\mathrm{M}+2 \mathrm{H}]^{+2}(\mathrm{~m} / \mathrm{z} 503)$ ions of the peptide AS( $p$ )TTVSKTE. Fragment ions observed with a loss of 98 are labeled with an asterisk $\left(^{*}\right)$ and ions that correspond to a loss of 18 from b-type fragment ions are labeled with an $x$.

\section{Conclusions}

Previous experiments that utilized FAB ionization for this work were hampered by inefficient ionization of the phosphorylated peptides [28]. Use of ESI, however, provides sufficiently strong ion currents for facile tandem mass spectrometry. The data presented here demonstrate the complementary use of different ESIMS/MS experiments. For these peptides, a combination of $(+)$ ESI- and ( - ESI-MS/MS, along with examination of different positive charge states by CID gave information that was inaccessible in a single tandem mass spectrometry experiment. Such a strategy could be of more general use for "problem" peptides for which fragmentation appears to be localized to just one segment of the peptide chain.

Previously, Ohguro et al. [25] studied phosphorylation of rhodopsin by the use of ESI-MS/MS for proteolytic peptides from the protein's C-terminal region. Isolated phosphorylated analogs of the peptides TSQVAPA and ASTTVSKTE were studied by tandem mass spectrometry. However, for the phosphorylated peptides, unambiguous determinations of sites of a

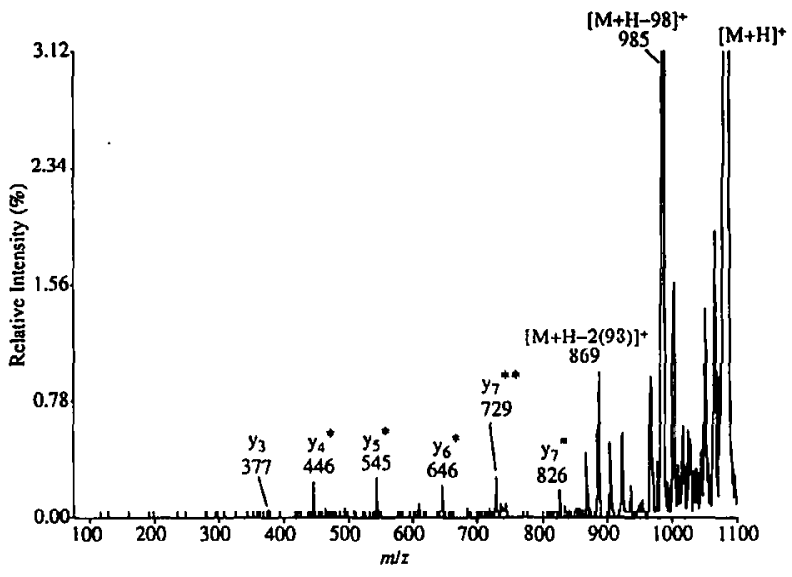

b

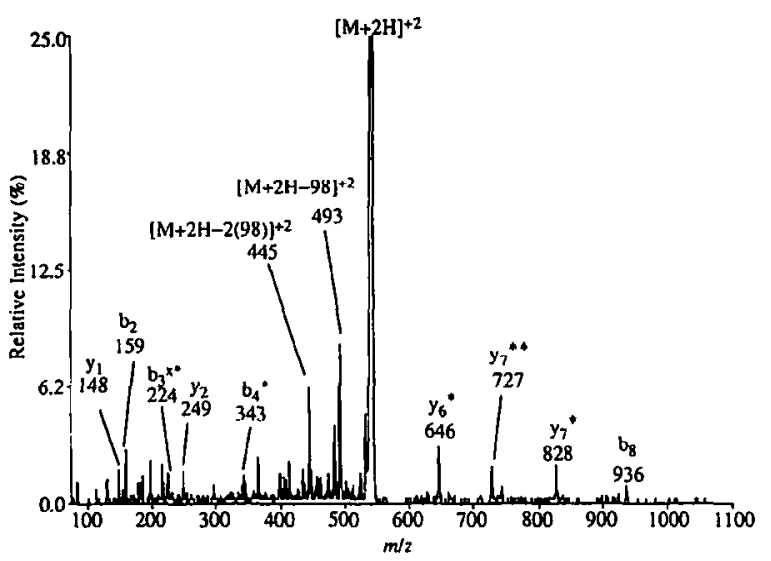

Figure 5. Product ion spectra for the (a) $[\mathrm{M}+\mathrm{H}]^{+1}(m / z$ 1084) and (b) $[\mathrm{M}+2 \mathrm{H}]^{+2}(\mathrm{~m} / 2$ 543) ions of the peptide AST(p)TVS(p)KTE. Fragment ions observed with a loss of 98 are labeled with an asterisk (*) and ions corresponding to a loss of 18 from b-type fragment ions are labeled with an $x$.

phosphorylation were not always obtained, due to a lack of observed collision-induced dissociations between potential phosphorylation sites. In their studies, Ohguro et al. did not present results of multiple forms of the ESI-MS/MS experiment (positive versus negative modes, singly versus doubly charged parent ions).

The results of the CID experiments with $[\mathrm{M}-\mathrm{H}]^{-1}$ ions of the TSQVAPA peptides exemplify the potential for the utility of the $(-)$ CID experiment with peptides. However, the complexity of results from $(-)$ CID, as indicated by the spectra that result from the experiments with the ASTTVSKTE analogs, shows the type of difficulty that has prevented ( - )CID from becoming routine for peptide analysis. The natural fit of negative mode ionization with CID of phosphorylated peptides, as demonstrated previously [9], makes further refinement of the (-)ESI-MS/MS technique particularly attractive.

The complementary use of different forms of the ESI-MS/MS experiment has been utilized to determine sites of phosphorylation in synthetic phosphopeptides based on sequences from the C-terminal region of rhodopsin accessible by enzymatic digestion. Sites of phosphorylation for many of these phosphopeptides 
could be determined, but difficulties in the application of (-)ESI-MS/MS to peptide sequencing remain. In particular, the ability of certain amino acids to direct the mode of fragmentation from processes that cause backbone fragmentation to processes that promote side chain cleavages requires futher study [32]. These difficulties represent a significant challenge for the structure elucidation of peptides for which negative mode ESI would appear to be the method of choice.

\section{Acknowledgments}

We thank Dr. Peter Moeller at the National Marine Fisheries Service, Southeastern Laboratory, Charleston, SC for use of the Sciex API III. This work was supported in part by NIH Grants EY 08239 and HL 07260 (postdoctoral fellowship for MB).

\section{References}

1. Cohen, P.; Gibson, B. W.; Holmes, C. F. B. Methods Enzymol. 1991, 201, 153-168.

2. Carr, S. A.; Hemling, M. E.; Bean, M. F.; Roberts, G. D. Anal. Chem. 1991, 63, 2802-2824.

3. Biemann, K. Biomed. Environ. Mass Spectrom. 1988, 16, 99-111.

4. Burlingame, A. L.; Boyd, R. K.; Gaskell, S. J. Anal. Chem. 1994, 66, 634R-683R.

5. Petrilli, P.; Pucci, P.; Morris, H. R.; Addeo, F. Biochem. Biophys. Res. Commun. 1986, 140, 28-37.

6. Poulter, L.; Ang, S.-G.; Williams D. H.; Cohen, P. Biochim. Biophys. Acta 1987, 929, 296-301.

7. Yip, T.-T.; Hutchens, T. W. FEBS Lett. 1992, 308, 149-153.

8. Schroeder, W.; Covey, T.; Hucho, F. FEBS Lett. 1990, 273, 31-35.

9. Gibson, B. W.; Cohen, P. Methods Enzymol. 1990, 193, 480-501.

10. Chait, B. T.; Kent, S. B. H. Science 1992, 257, 1885-1894.

11. Gibson, B. W.; Falick, A. M.; Burlingame, A. L.; Nadasdi, L.; Nguyen, A. C.; Kenyon, G. L. I. Am. Chem. Soc. 1987, 109, 5343-5348.

12. Poulter, L.; Ang, S.-G.; Gibson, B. W.; Williams, D. H.; Holmes, C. F. B.; Caudwell, F. B.; Pitcher, J.; Cohen, P. Eur. J. Biochem. 1988, 175, 497-510.

13. Yang, H.-Y.; He, M.-Y.; Ye, Y.-H.; Zhao, Y.-F. Org. Mass Spectrom. 1992, 27, 746-749.
14. Michel, H.; Hunt, D. F.; Shabanowitz, J.; Bennett, J. J. Biol. Chem. 1988, 263, 1123-1130.

15. Michel, H.; Griffin, P. R.; Shabanowitz, J.; Hunt, D. F.; Bennett, J. J. Biol. Chem. 1991, 266, 17584-17591.

16. Alexander, I. E.; Hunt, D. F.; Lee, M. K.; Shabanowitz, J.; Michel, H.; Berlin, S. C.; Macdonald, T. L.; Sundberg, R. J.; Rebhun, L. I.; Frankfurter, A. Proc. Natl. Acad. Sci. USA 1991, 88, 4685-4689.

17. Nijenhuis, A. A.; Fikkens, R. H.; Nibbering, N. M. M.; van Oijen, A. H.; de Bont, H. B. A.; Liskamp, R. M. J.; van Boom, J. H. Rapid Commun. Mass Spectrom. 1993, 7, 774-779.

18. Covey, T.; Shushan, B.; Bonner, R.; Schroder, W.; Hucho, F. Methods in Protein Sequence Analysis; Jornvall, H.; Hoog, J.-O.; Gustavsson, A.-M., Eds.; Birkhauser: Basel, 1991.

19. Huddleston, M. J.; Annan, R. S.; Bean, M. F.; Carr, S. A. I. Am. Soc. Mass Spectrom. 1993, 4, 710-717.

20. Rossomando, A. J.; Wu, J.; Michel, H.; Shabanowitz, J.; Hunt, D. F.; Weber, M. J.; Sturgill, T. W. Proc. Natl. Acad. Sci. USA 1992, 89, 5779-5783.

21. Hou, J.; McKeehan, K.; Kan, M.; Carr, S. A.; Huddleston, M. J.; Crabb, J. W.; McKeehan, W. L. Protein Sci. 1993, 2, 86-92.

22. Hunter, A. P.; Games, D. E. Rapid Commun. Mass Spectrom. $1994,8,559-570$.

23. Taniguchi, H.; Suzuki, M.; Manenti, S.; Titani, K. J. Biol. Chem. 1994, 269, 22482-22484.

24. Meins, M.; Jeno, P.; Muller, D.; Richter, W. J.; Rosenbusch, J. P.; Erni, B. J. Biol. Chem. 1993, 268, 11604-11609.

25. Ohguro, H.; Palczewski, K.; Ericsson, L. H.; Walsh, K. A.; Johnson, R. S. Biochemistry 1993, 32, 5718-5724.

26. Palczewski, K.; Buczylko, J.; VanHooser, P.; Carr, S. A.; Huddleston, M. J.; Crabb, J. W. J. Biol. Chem. 1992, 267, 18991-18998.

27. Ohguro, H.; Johnson, R. S.; Ericsson, L. H.; Walsh, K. A.; Palczewski, K. Biochemistry 1994, 33, 1023-1028.

28. Papac, D. I.; Oatis, J. E.; Crouch, R. K.; Knapp, D. R. Biochemistry 1993, 32, 5930-5934.

29. Knapp, D. R.; Oatis, J. E.; Papac, D. I. Int. J. Peptide Protein Res. 1993, 42, 259-263.

30. Loo, J. A.; Ogorzalek Loo, R. R.; Light, K. J.; Edmonds, C. G.; Smith, R. D. Anal. Chem. 1992, 64, 81-88.

31. Bradford, A. M.; Waugh, R. J.; Boie, J. H. Rapid Commun. Mass Spectrom. 1995, 9, 677-685.

32. Waugh, R. J.; Bowie, J. H. Rapid Commun. Mass Spectrom. 1994, 8, 169-173. 